\section{El peligro de Staphylococcus aureus resistente a la vancomicina}

Staphylococcus aureus es una de las causas más comunes de infección nosocomial o adquirida en la comunidad, la causa más común de la infección de heridas quirúrgicas y la segunda en importancia después de los estafilococos productores de coagulasa negativa en la infección nosocomial de la corriente sanguínea. Luego del éxito inicial que se logró contra S. aureus con la penicilina, comenzaron a surgir cepas del microorganismo resistentes a este antibiótico. Actualmente, de 70 a $80 \%$ de los S. aureus aislados son resistentes a la penicilina. Estas cepas se trataron con meticilina y otras penicilinas semisintéticas hasta los años ochenta, cuando $S$. aureus resistente a la meticilina se volvió endémico en muchos hospitales. Desde entonces, el único tratamiento efectivo contra las infecciones por estafilococos ha sido el glucopéptido vancomicina. Sin embargo, la reciente emergencia de resistencia a los glucopéptidos en estafilococos productores de coagulasa negativa ha producido gran preocupación en la comunidad médica por la posibilidad de que S. aureus también desarrolle resistencia a los glucopéptidos. En ese caso, las tasas de morbilidad y mortalidad por $S$. aureus podrían ascender de nuevo a cifras similares a las que existían antes de tener antibióticos.

Las primeras infecciones por S. aureus con resistencia intermedia a glucopéptidos se documentaron, una en el Japón en 1996 y dos en los Estados Unidos en 1997. Un cuarto caso descubierto recientemente en Nueva York completa el total de infecciones por $S$. aureus con resistencia intermedia a glucopéptidos que se han documentado. A pesar del bajo número de casos, se observan en ellos varios rasgos en común. Los cuatro pacientes tuvieron infecciones previas con $S$. aureus resistente a la penicilina, para las cuales fueron tratados por largo tiempo con vancomicina. Los cuatro recibieron diálisis y, en tres, la respuesta clínica a la terapia con vancomicina fue insatisfactoria. Parecería lógico, entonces, vigilar dicha resistencia en pacientes que a menudo se tratan con vancomicina, como los de diálisis. Por otra parte, fue muy difícil erradicar la infección en los cuatro pacientes mencionados, por lo cual el Comité Asesor de Prácticas de Control de Infecciones recomienda una serie de medidas preventivas. El uso profiláctico ordinario de la vanco- micina debe desaconsejarse para pacientes quirúrgi$\cos \sin$ alergias graves a antibióticos betalactámicos; recién nacidos de bajo peso; y pacientes en diálisis, con neutropenia y con catéteres centrales venosos. También se desaconseja para el tratamiento empírico de pacientes febriles con neutropenia que no están en riesgo de infección por bacterias grampositivas resistentes y recién nacidos de bajo peso febriles; descontaminación del aparato digestivo; y los siguientes grupos de pacientes: con serología positiva a estafilococos coagulasa-negativos; infectados por $S$. aureus resistente a la meticilina, con colitis por Clostridium difficile, en diálisis con infecciones que deben tratarse y con infecciones grampositivas no debidas a organismos resistentes. Para evitar la dispersión de estafilocos resistentes a glucopéptidos, se recomienda seguir las medidas de seguridad de laboratorio de los Centros para el Control y la Prevención de Enfermedades en Atlanta, Georgia, Estados Unidos, aislar al paciente en un cuarto privado; reducir a un mínimo el número de personas que lo atienden; iniciar investigaciones epidemiológicas y de laboratorio, educar al personal de salud sobre la epidemiología de $S$. aureus con resistencia intermedia a los glucopéptidos y sobre las precauciones convenientes, hacer obligatorio el cumplimiento de las precauciones preventivas sobre contacto con el paciente; verificar si ha ocurrido transmisión mediante el cultivo de especímenes de manos y nariz de todas las personas en contacto físico con el paciente, los que le prestan la atención de salud y los compañeros de habitación; tomar precauciones de contacto (con mascarillas, batas, guantes y jabón antibacteriano para el lavado de manos); consultar con las autoridades de salud antes de dar de alta al paciente o transferirlo a otra institución, e informar al personal encargado de recibir pacientes de la presencia de un caso de $S$. aureus resistente. (Smith TL, Pearson ML, Wilcox KR, Cruz C, Lancaster MV, Robinson-Dunn B, et al. Emergence of vancomycin resistance in Staphylococcus aureus. New Engl J Med 1999;340(7):493-501.)

\section{Posición de la OMS sobre las vacunas antirrotavirus}

La infección por rotavirus ocurre en todas partes del mundo y es la causa más común de diarrea grave en los niños pequeños. Casi todos ad- 
quieren la infección antes de la edad de 3 a 5 años y anualmente se atribuyen a esa causa más de 125 millones de casos de diarrea. Se estima que los rotavirus causan $25 \%$ del total de muertes debidas a enfermedades diarreicas y $6 \%$ de todas las muertes de niños menores de 5 años. La enfermedad tiene un período de incubación de 1 a 2 días y se caracteriza por la aparición súbita de vómitos, fiebre y diarrea acuosa profusa. Si bien la infección suele ser benigna y produce inmunidad, las formas graves que no se tratan pueden inducir una deshidratación mortal. El peso de esta enfermedad es mayor en los países en desarrollo, donde anualmente produce de 20 a $40 \%$ de las hospitalizaciones por diarrea infantil y unas 600000 muertes. En los países industrializados, la mayor parte de los casos graves ocurren pasado el primer año de vida. En Australia, Estados Unidos, Gales, Inglaterra y Japón, la infección por rotavirus está implicada en 34 a 52\% de las hospitalizaciones por gastroenteritis infantil, pero la mortalidad por diarrea es rara en esos países.

En los países tropicales en desarrollo, la enfermedad por rotavirus ocurre durante todo el año. Varios serotipos pueden manifestarse simultáneamente en la misma zona geográfica y la infección de un solo paciente por varias cepas virales es común. En cambio, en los países industrializados de clima templado, las infecciones por rotavirus llegan al máximo en el invierno y rara vez se observan infecciones mixtas. Los rotavirus se transmiten por la vía fecal-oral y un pequeño inóculo es suficiente para provocar una infección. No se conocen reservorios animales para el virus humano y los portadores asintomáticos no parecen ser una fuente importante de casos esporádicos. Los rotavirus pueden provocar infecciones nosocomiales en los niños y se asocian con la diarrea de los viajeros, las personas de edad y las personas que cuidan a niños pequeños. No hay una gran diferencia entre los países en desarrollo y los industrializados en cuanto a la incidencia de rotavirus. Por lo tanto, no es un problema susceptible de mejora por medio de cambios en el medio ambiente. No obstante, la mortalidad por rotavirus se reduce según aumenta el estándar de vida. La rehidratación oral es el tratamiento indicado, pero no reduce la diseminación del virus y actualmente no hay quimioterapia específica contra rotavirus.

Por la importancia mundial de los rotavirus como problema de salud pública, la OMS ha otorgado alta prioridad al desarrollo de una vacuna. Actualmente hay siete vacunas antirrotavirus en elaboración, pero solo una ha sido autorizada para uso en los Estados Unidos de América, la vacuna oral tetravalente de rotavirus de monos rhesus (RRV-TV). Esta vacuna demostró su eficacia para prevenir diarrea grave por rotavirus en niños menores de 2 años en estudios realizados en los Esta- dos Unidos, Finlandia y Venezuela. El ensayo de una dosis 10 veces menor en el Brasil y el Perú no tuvo un efecto protector satisfactorio, lo que hace pensar que el resultado pueda estar relacionado con la dosis. Sin embargo, las bajas tasas de enfermedad grave en esos estudios complica la interpretación de los resultados. La RRV-TV es inocua y fácil de adaptar a los programas nacionales de inmunización y su inclusión en los programas de los países industrializados sería una buena forma de comenzar el control mundial de los rotavirus. La incidencia de diarrea grave y mortal por rotavirus es especialmente alta en los países en desarrollo, pero la OMS considera prematuro incluir la RRV-TV en los programas de esos países. En consecuencia, no se desaconseja la vacunación en escala limitada para protección individual tal como se practica en el sector privado, pero se considera necesario llevar a cabo estudios en África y Asia antes de confirmar su eficacia en una variedad de localidades del mundo en desarrollo. (Organización Mundial de la Salud. Rotavirus vaccines: WHO position paper. Wkly Epidemiol Rec 1999;74:33-38.)

\section{Tratamiento de bajo costo frena la transmisión vertical de VIH}

Un extenso estudio en el que participaron tres países africanos ha brindado las pruebas más convincentes hasta ahora de que un tratamiento relativamente sencillo y barato puede reducir la transmisión del virus de la inmunodeficiencia humana (VIH) de las embarazadas infectadas a sus hijos. El estudio, que se conoce por la sigla PETRA, mostró también que una variación del tratamiento es ineficaz, conclusión a la que los investigadores solo pudieron llegar comparando tres regímenes diferentes con el de placebo.

El estudio fue patrocinado y financiado principalmente por el Programa Conjunto de las Naciones Unidas sobre el Sida (ONUSIDA) e incluyó a 1792 embarazadas positivas a VIH de Suráfrica, Tanzania y Uganda, que convinieron voluntariamente en poner a prueba la capacidad de prevenir la transmisión de los medicamentos anti-VIH que se conocen como AZT y 3TC. En la 6a Conferencia sobre Retrovirus e Infecciones Oportunistas celebrada en Chicago del 31 de enero al 4 de febrero de 1999, se presentó un análisis preliminar de las pruebas llevadas a cabo en 1326 niños a las 6 semanas de edad, el cual mostró que dos tipos de tratamiento habían sido efectivos. La estrategia más intensiva — de tratar a las madres con los dos medicamentos desde la semana 36 del embarazo hasta una semana después del parto y al bebé por una semana- redujo el riesgo de transmisión en $50 \%$. Solamente $8,6 \%$ de los 
recién nacidos se infectaron, comparados con $17,2 \%$ en el grupo que recibió placebo. Cuando se aplicó el mismo tratamiento al comienzo del parto, la tasa de transmisión se redujo a 10,8\%, una reducción del riesgo de $37 \%$. Este avance es de gran importancia para los países en desarrollo, donde las mujeres pobres no buscan asistencia hasta que empieza el parto. En un ensayo más pequeño llevado a cabo en Tailandia en 1998, el tratamiento de la madre por 4 semanas antes del parto redujo la transmisión en 50\% (Science, 27 de febrero de 1998, p. 1299).

En 1997, el ensayo PETRA fue censurado por personas que lo tildaron de poco ético debido al uso de placebo. Los críticos adujeron que un estudio realizado en los Estados Unidos y Francia en 1994 había convertido el uso posterior de placebo en una acción inmoral. El estudio indicaba que si se trataba a la madre con AZT por un promedio de 11 semanas antes del parto, se le administraba el mismo medicamento por vía intravenosa durante el parto y se trataba al bebé por 6 semanas después de nacido, la transmisión se podía reducir de $22,5 \%$ en el grupo de control a 8,3\%, disminución de casi $70 \%$. Aunque los críticos del PETRA estuvieron de acuerdo con que esta intervención era muy costosa y complicada para aplicarla en los países pobres, alegaron que debía usarse como criterio con el cual comparar otros regímenes más sencillos (Science, 16 de mayo de 1997, p. 1022). Los investigadores de PETRA señalan, sin embargo, que ese comportamiento hubiera llevado a conclusiones erróneas y peligrosas. Una tercera parte del estudio, en la cual la madre recibía tratamiento desde el inicio del parto y el bebé no recibía ninguno, dio una tasa de transmisión de $17,7 \%$, mejor que la de $25,5 \%$ del grupo no tratado. Si ese estudio hubiera constituido el único punto de comparación, se podría haber llegado a la conclusión de que el tratamiento aplicado al comenzar el parto funcionaba muy bien. En el estudio PETRA, la tasa de transmisión en el grupo de placebo fue casi igual a la del grupo de mujeres que recibieron ese tipo de tratamiento. Así, sin el grupo control de placebo nunca se habría podido observar que el tratamiento durante el parto solamente no tiene efecto. Aun así, los detractores del estudio piensan que pudo haberse llegado a la misma conclusión de una forma que protegiera más a las pacientes. Unos alegan que debió saberse de antemano que el tratamiento durante el parto no tendría efecto porque los medicamentos contra VIH tardan varios días en acumularse lo suficiente para surtir efecto. Otros contestan que el AZT se transmite rápidamente de la madre al feto $\mathrm{y}$, aunque tarde varios días en llegar a una concentración máxima, siempre tiene algún efecto desde el principio.

El estudio PETRA continuará. Cerca de $70 \%$ de las madres participantes amamantan a sus hijos, lo que constituye otra ruta de transmisión del virus. Los investigadores volverán a analizar las tasas de transmisión cuando los niños cumplan 18 meses de edad. (Cohen J. Cheap treatment cuts HIV transmission. Science 1999;283:916-917.)

\section{El origen fetal de la diabetes mellitus tipo 2}

Pese a que los genes tienen gran influencia en el crecimiento de un feto, diversos estudios en seres humanos y animales parecen indicar que ese crecimiento se ve limitado por factores ambientales, especialmente por los nutrientes y el oxígeno que el feto recibe. Desde el punto de vista de la evolución, hay muchas posibles ventajas en esa tendencia del cuerpo a permanecer plástico durante su desarrollo en vez de regirse rígidamente por las instrucciones genéticas adquiridas en la concepción. Los estudios de animales indican que el feto puede adaptarse a la malnutrición alterando su producción hormonal o la sensibilidad de los tejidos a las hormonas. Entre las hormonas que regulan el crecimiento fetal y, por lo tanto, la necesidad de nutrientes, la insulina tiene una función central. El feto puede alterar su metabolismo, por ejemplo, cambiando de oxidación glucosa a la de aminoácidos. Puede también redistribuir la producción cardíaca para proteger los órganos más importantes como el cerebro. Incluso puede adaptarse a un crecimiento más lento para disminuir las exigencias de sustrato. Sin embargo, al contrario de las adaptaciones fisiológicas que ocurren en el adulto, las del feto llevan a cambios permanentes en la estructura y función del cuerpo. En experimentos con animales se ha observado que hasta modificaciones muy pequeñas en la dieta de animales preñadas pueden dar lugar a cambios en las crías que duran toda la vida y pueden compararse con enfermedades humanas como la hipertensión y la alteración del metabolismo glucosainsulina. En el nivel molecular, estos cambios "programados" quizá reflejen la alteración de la expresión de los genes in útero de acuerdo con la disponibilidad de nutrientes, que actúa directamente en la célula o por medio de señales hormonales.

A principio de los años noventa, un estudio llevado a cabo en Hertfordshire, Inglaterra, mostró por vez primera que las personas con bajo peso al nacer tenían tasas más altas de diabetes tipo 2 que otras personas al llegar a adultos. El estudio fue parte de un programa de investigación sobre la hipótesis de los orígenes fetales, la cual declara que la enfermedad coronaria, los accidentes cardiovasculares, la diabetes tipo 2 y la hipertensión se originan en adaptaciones del feto a la malnutrición. Esas adaptaciones causan cambios permanentes en la estructura y fisiología del organismo. En el estudio se 
examinaron hombres y mujeres nacidos entre 1911 y 1930, de los cuales se había registrado el peso al nacer y durante la niñez temprana. Más tarde, otros estudios en Europa y los Estados Unidos confirmaron la asociación entre el bajo peso al nacer y el desarrollo de diabetes tipo 2 o tolerancia reducida a la glucosa.

El peso al nacer sirve como indicador del crecimiento y la nutrición fetales, pero de forma muy poco exacta. El mismo peso al nacer puede representar muchas vías de crecimiento diferentes. Las mediciones detalladas del tamaño del cuerpo al nacer dan una mejor idea de las adaptaciones fetales. Por ejemplo, los niños de bajo peso al nacer que se mantienen delgados tienen la tendencia a ser resistentes a la insulina en su niñez y adultez y más propensos a desarrollar diabetes mellitus tipo 2. Esto sugiere que los niños delgados respondieron in útero a la malnutrición mediante cambios endocrinos y metabólicos. Los datos más extensos sobre el tema se publicaron en 1998 y fueron parte de los resultados de un estudio sobre la salud de un grupo grande de enfermeras. En esa ocasión se verificaron los resultados anteriores pero de forma más fidedigna, ya que pudieron hacerse ajustes por factores de nivel socioeconómico y modos de vida. Por otra parte, ese estudio parece verificar que las embarazadas con diabetes gestacional tienden a tener niños de peso alto que también están en riesgo de diabetes tipo 2, lo cual no se aplica a otras personas con sobrepeso.

A pesar de los argumentos esgrimidos en contra de la hipótesis de los orígenes fetales, los experimentos con animales la apoyan. Si la diabetes tipo 2 es consecuencia de una adaptación in útero, obviamente la prevención primaria consiste en proteger el desarrollo fetal. Los estudios epidemiológicos futuros necesitan emplear indicadores de ese desarrollo más exactos que el peso al nacer. Vale la pena explorar los mecanismos mediante los cuales la desnutrición y el retraso del crecimiento in útero producen cambios que influyen en el metabolismo glucosa-insulina, pues la diabetes tipo 2 es ya una epidemia de alcance mundial. (Parker DJP. The fetal origins of type 2 diabetes mellitus. Ann Intern Med 1999;130(4 part 1):322-323.)

\section{El enriquecimiento de harinas en Venezuela}

La crisis económica que se inició en Venezuela en 1983 trajo consigo el deterioro progresivo de la cantidad y la calidad de los alimentos consumidos por $78 \%$ de la población. Según la información recaudada por el Instituto Nacional de Nutrición, los nutrientes más necesitados son el hierro, las vitaminas del complejo B y la vitamina A. En 1991, dicho Instituto inició un estudio de factibili- dad del enriquecimiento de la harina de maíz precocida, alimento popular de producción íntegramente nacional, que se consume en forma de arepa en todo el país y especialmente por los sectores de bajo nivel socioeconómico. La harina de maíz precocida se introdujo en 1962, representa $15 \%$ del aporte de calorías y $11 \%$ de las proteínas con respecto al total de la dieta y figura en primer lugar entre los alimentos de mayor consumo en el país. Constituía, por lo tanto, el vehículo ideal para el enriquecimiento propuesto. Tras muchos estudios de los suplementos necesitados en la dieta, se decidió que a toda la harina de maíz precocida producida en Venezuela deberían añadirse, con carácter obligatorio, cantidades determinadas de vitamina A; tiamina; riboflavina; niacina y hierro para aportar $25 \%$ de los nutrientes diarios recomendados, teniendo en cuenta las pérdidas provocadas por la cocción. Esas cantidades se variaron ligeramente para obtener resultados óptimos en la nutrición y en la preparación de arepas.

En noviembre de 1992, la Asociación Venezolana de Productores de Trigo presentó voluntariamente un perfil de enriquecimiento de la harina de trigo destinada a la fabricación de pan. En 1993 se inició un programa obligatorio de enriquecimiento con tiamina, riboflavina, niacina y hierro. El control del enriquecimiento de ambas harinas está a cargo del Instituto Nacional de Higiene y el Instituto Nacional de Nutrición Rafael Rangel, los cuales llevan a cabo un muestreo regular que abarca todo el país. También se mantiene una vigilancia constante en las plantas para controlar el funcionamiento de los dosificadores de premezcla y el empacado de los productos finales.

Una encuesta realizada en la zona metropolitana de Caracas en 1994 en una población de 317 niños de 7, 11 y 15 años mostró que la prevalencia de deficiencia de hierro determinada por la concentración de ferritina sérica y la prevalencia de anemia, habían disminuido de 37 y $18 \%$, respectivamente, en 1992 a 16 y 10\%, respectivamente. Además, entre fines de 1996 y principios de 1997, se hizo en Caracas una encuesta preliminar de 561 niños de ambos sexos de 7, 11 y 15 años de edad pertenecientes a los estratos de bajo nivel socioeconómico, en los que se encontró una prevalencia de anemia de 5,1\%. Es interesante destacar el efecto protector de la vitamina A contra los fitatos que contiene la harina precocida de maíz, lo que favorece la absorción del hierro. Cabe observar que no se ha puesto en marcha ningún otro programa nutricional a partir de 1994 y que el costo del enriquecimiento de ambas harinas es de US $\$ 0,11$ por persona al año. Esta experiencia alentadora es un ejemplo de lo que puede lograrse mediante un buen trabajo en equipo y decisiones oportunas por parte 
de las autoridades oficiales, así como de cooperación efectiva entre el sector oficial y la empresa privada. (Chávez JF, González Gamero E. Resultados de una experiencia exitosa: el enriquecimiento de harinas en Venezuela. Interciencia 1998;23(6):338-342.)

\section{Se extiende el nuevo modelo "hospitalista" en los Estados Unidos}

La revista Annals of Internal Medicine acaba de dedicar un suplemento especial del número de la revista 130(4), 16 de febrero de 1999, a describir un nuevo movimiento en atención hospitalaria que se está convirtiendo rápidamente en objeto de rigurosos análisis y estudios en los Estados Unidos. Se trata del modelo bautizado con el nombre de "hospitalista" en 1996 para referirse al médico que dedica gran parte de su tiempo y atención al cuidado de pacientes hospitalizados. Si bien siempre han existido especialistas de base hospitalaria en Europa y los Estados Unidos, los hospitalistas representan un nuevo paradigma en torno a la noción de hand-off o no interferencia por parte del médico de atención primaria. El hospitalista representa un médico autónomo sin las presiones y responsabilidades que tienen los médicos de consultorio. En teoría, esa característica podría beneficiar al paciente por medio de un cuidado más eficiente en el hospital, internaciones más cortas, ahorros y una calidad mejor de atención. Puesto que pasa mucho tiempo en el hospital, el hospitalista podría también asumir funciones de consultor médico, gerente de asuntos relacionados con cirugía, instructor de estudiantes de medicina y personal intrahospitalario e incluso de administrador en cuanto al desarrollo de normas clínicas y pasos críticos, mejora de la calidad y evaluación del uso de recursos. El aporte a estas áreas por parte de médicos dedicados representaría un gran avance.

Cerca de $90 \%$ de los hospitalistas miembros de la National Association of Inpatient Physicians, nueva asociación nacional de médicos de pacientes hospitalizados, son internistas y la mayor parte recién empiezan su carrera. Para muchos internistas de experiencia, la práctica médica ha cambiado a medida que el foco de su atención se desplaza a una modalidad ambulatoria y, en muchos casos, a la atención primaria. Quizá en estos casos la disponibilidad de atención hospitalista para sus pacientes les permitirá vivir de manera menos fragmentada, abandonar la ineficiencia de ver muy pocos pacientes hospitalizados y concentrarse en mejorar la práctica basada en el consultorio o en el cuidado domiciliario e invertir más tiempo en la enseñanza desde el consultorio. Para que todo esto tenga un resultado satisfactorio, se requiere una comunicación excelente entre el internista y el hospitalista que se hace cargo de sus pacientes. Todavía es muy pronto para saber si ello es factible. A los desconfiados, el movimiento hospitalista puede parecerles otro paso más en el proceso de subespecialización y fragmentación de la medicina interna. Dadas las exigencias de la vida profesional fuera de los hospitales, muchos internistas ya ceden grandes proporciones de su responsabilidad a médicos de urgencias, consultores institucionales y otro personal de los hospitales. El grueso de la enseñanza a menudo se deja en las manos de asistentes y se imparte con frecuentes conferencias. En las facultades de las escuelas de medicina se suele separar a los clínicos de los investigadores para asegurarse de que haya una continua productividad de conocimientos académicos. Además, teniendo en cuenta que el interés principal debe ser la continuidad del cuidado del paciente, si no hay buena comunicación entre el médico remitente y el hospitalista antes, durante y después de la hospitalización, la calidad de la atención y la relación entre el paciente y el médico de atención primaria se deteriorará. Para muchos pacientes, no poder contar con la cercanía de su médico personal puede ser un precio demasiado alto que pagar, por más eficiente que sea el cuidado que recibe en el hospital. A la vez que prolifera el modelo del hospitalista, se debaten preguntas como las siguientes: ¿Deben los hospitalistas trabajar solamente cuidando enfermos en el hospital? ¿Debe todo el cuidado intrahospitalario estar a cargo de hospitalistas o compartirse con un pequeño cuadro de proveedores de atención primaria? ¿Deben los hospitalistas del futuro ser médicos generales o especialistas? ¿Quién debe ser el empleador de los hospitalistas y cómo deben ser remunerados? ¿Cómo deben ser formados los hospitalistas? ¿Es el nuevo hospitalista un especialista y, si es así, qué implica ello para la medicina organizada, el personal de salud, las organizaciones que otorgan credenciales y la medicina académica? (Goldmann DR. The hospitalist movement in the United States: what does it mean for internists? Ann Intern Med 1999;130(4 part 1):326-327 y Wachter RM. An introduction to the hospitalist model. Ann Intern Med 1999;130(4 part 2):338-342.)

\section{La anticoncepción de urgencia}

Hace ya casi 25 años que Yuzpe publicó su trabajo en torno al uso de estrógeno y progestágeno para anticoncepción de urgencia. Este método evita tres de cada cuatro embarazos que habrían ocurrido sin tratamiento. Hace unos meses, la OMS verificó que el uso de levonorgestrel solo es efectivo y tiene menos efectos secundarios que la combinación de estrógeno y progestágeno. Esta produce náusea y 
vómitos, pero por lo demás es inocua. La OMS ha indicado que no hay contraindicaciones al nuevo medicamento aunque las últimas guías publicadas por el Real Colegio de Obstetras y Ginecólogos de Inglaterra todavía consideran contraindicaciones relativas los antecedentes de tromboembolia y la migraña, y contraindicación absoluta la historia de migraña con aura.

Desde la publicación original de Yuzpe no se ha trabajado más en cuestiones de dosis y tiempo de administración. Por otra parte, se ha trabajado sobre varios medicamentos alternativos. La mifepristona resultó muy eficaz, pero la dosis de $600 \mathrm{mg}$ perturba el ciclo de forma considerable. En estudios ulteriores se comprobó la eficacia de dosis más bajas, pero la mifepristona no está ampliamente disponible ni parece que lo estará en el futuro cercano debido a su asociación con el aborto inducido. El donazol, que se probó por corto tiempo, resultó ineficaz. De modo que los datos sobre el levonorgestrel constituyen una novedad atrayente, ya que mostraron por lo menos igual y quizá más eficacia en comparación con la combinación de estrógeno y progestágeno y menos efectos secundarios. Sin embargo, la British Medical Journal advierte a los médicos ingleses que, antes de cambiar impulsivamente de uno a otro medicamento, hay varios factores que considerar. Uno es que en el Reino Unido no hay ningún producto de uso autorizado que contenga solo levonorgestrel $\mathrm{y}$, como muchas de las consultas sobre anticoncepción de urgencia se dirigen a enfermeras, quienes solo pueden recetar por medio de protocolos - que toman tiempo preparar- un cambio muy rápido afectaría a los servicios que se ofrecen. Otro punto es que las mujeres tienen que tomar dos dosis de 25 tabletas cada una, conducta poco conveniente que puede reducir el cumplimiento. Además, la biodisponibilidad de 50 tabletas quizá no sea igual a la de dos. De todos modos, las autoridades reguladoras de medicamentos deberían dar prioridad muy alta al levonorgestrel. Aun más importante, mientras más pronto se toma el medicamento, más eficaz es. Esto tiene ciertas implicaciones para los proveedores de servicios. A los médicos generales no les gusta recibir llamadas nocturnas; los servicios de accidentes y urgencias están más que ocupados y no son lugares ideales para hablar de la salud sexual; y las clínicas de planificación familiar no están abiertas a todas horas. Una opción es ofrecerlas en las farmacias. En 1995 el colegio y el profesorado emitieron una declaración conjunta pidiendo que los anticonceptivos hormonales de urgencia se reclasificaran de "por prescripción solamente" a "de venta libre en farmacias". Por otro lado, este tipo de medicamento de podría entregar con anticipación a quienes puedan necesitarlo. Algunos estudios muestran que la autoadministración voluntaria no lleva necesariamente a su abuso. Si los anticonceptivos de urgencia se aprueban para venta general en las farmacias, tienen que estar acompañados de mensajes muy claros sobre cómo adquirir anticoncepción más eficaz de largo plazo. En el Reino Unido, deben distribuirse gratis por las vías acostumbradas.

La disponibilidad de levonorgestrel no hará obsoleta la combinación de estrógeno y progestágeno. La mayor parte de los países no tienen ninguna forma aprobada de anticonceptivos de urgencia pero tienen píldoras combinadas que en muchos de ellos pueden obtenerse sin prescripción. Las de progestágeno solo son menos comunes y más caras. Para efectividad, el anticonceptivo de elección es el dispositivo intrauterino y a pesar de ello no se ofrece regularmente, aun en el Reino Unido. Se necesita educar e informar mejor a los trabajadores de salud y a las mujeres, para que elijan lo mejor. (Webb A. Emergency contraception: is it time to change method? BMJ 1999;318:342-343.) 